\title{
Sexual (dis)orientation: gender, sex, desire and self-fashioning
}

Tasmin Wilton; Palgrave, London, 2004, 240p, ISBN 1-4039-0574-6 £15.00 (Pbk); ISBN 1-4039-0572-X £43.00 (Hbk)

Sexual (Dis)Orientation continues an already firmly established agenda in Tasmin Wilton's studies of human sexuality. Her previous publications, which include such titles as Finger Licking Good: The Ins \& Outs of Lesbian Sex (1996) and Unexpected Pleasures: Leaving Heterosexuality for a Lesbian Life (2002), have already clearly established Wilton's position within the fields of lesbian studies and human sexuality. Evidence of her location is equally present within Sexual (Dis)Orientation, not only in the opening 'declaration of self-interest' (pp. 23-53) - which also includes the now familiar feminist critique of notions of objectivity - but also throughout the subsequent chapters in which formerly heterosexual women discuss their experiences of a lesbian life.

Nonetheless, despite clear lesbian and feminist influences on her work (including a carefully traced history of such theorizations of sexuality), Wilton defines Sexual (Dis) Orientation primarily as a queer project. Initially, I found this definition somewhat perplexing, in that the text stems from a qualitative study in empirical sociology, and as such appeared rather alien to the post-modern, psychoanalytic and linguistic influences of queer theory. However, as the book progressed, I understood more clearly her choice of definition. Firstly, in that she emphasized the regulatory power of heteronormative/essentialist structures over women's understanding, choices, and experiences of their sexuality. Secondly, further evidence of a queer imperative surfaced in her identification of desire as the primary location from which to untangle the hegemonic regulation and control, power and inequalities inherent to the matrix of gender, sex and sexuality. Finally, a queer politic was also clearly evident in her adamant refusal of fixed, or 'orientationalist' (p. 35), categories of sexuality. Instead, Wilton emphasizes how categories of orientation result from essentialist discourses of medical science, and that sexuality itself is made up from the interplay of a number of discourses, experiences, choices and restraints which she later articulates within a conceptualization of 'taste' ( $p$. 191). Wilton elaborates on 'taste' through a rather beautiful analogy with food, which enables her to explore the ways in which apparently innate human responses, such as revulsion and desire, are culturally determined and also inseparable from power, control and hierarchy, alongside more mundane influences such as the availability of choice. She describes, for example, how lesbians, like avocados, were neither visible nor viable in the Cornwall of the 1950s where she passed her youth.

Wilton's theoretical analysis is based on empirical research with over 240 previously heterosexual lesbians. Also included in this figure is a small comparison sample of consistently heterosexual women. The chapters woven from this material commence in a largely upbeat tempo in which the lesbian 
participants reveal celebratory and affirming narratives of the pleasures and fulfilments of their current sexual identity (albeit often within the context homophobia at the macro and/or micro levels). However, later in the text, as Wilton returns to her queer project of interrogating heterosexuality, the mood radically changes. The chapters on heterosexuality present a depressing account of women's expectations and experiences of their sexuality, particularly within the context of an allegedly liberal, egalitarian culture. Overall, a picture emerges of female sexuality dominated by disappointment, resignation and low levels of expectation and fulfilment.

\footnotetext{
This group of women found men to be less than satisfactory intimate partners. They described familiar experiences of sexual disappointment, lack of communication or emotional literacy, and identified a range of social and cultural pressures on them to marry .... Participants were more likely to express a relatively low-key appreciation of men's bodies, coupled with a strong sense of sexual disappointment and an acknowledgement (more or less forgivingly expressed) that men tend to be emotionally unskilled and to have an instrumental, mechanistic, sexuality.
}

(pp. 132-4)

Wilton uses this rather bleak account of female sexuality to critique essentialist notions of innate differences between lesbian and heterosexual women, particularly by noting that both lesbian and heterosexual women shared such experiences, and, more surprisingly, that it was often the lesbian women who articulated a more positive account of their sexual relationships with men.

Overall, Wilton's robust critique of the essentialist positions which permeate cultural and individual discourses of self and sexuality, and their relationship to restrictive heteronormative constructions of sex/gender/sexuality, is an important and timely addendum to the ongoing medical/science domination in this field, and, is delivered throughout, with her characteristic wit and vitality. Indeed, reading through the contrasting portrayals of the delights of lesbian sexuality and the mundane disappointment of heterosex, I felt that Sexual (Dis)Orientation could function as a rather effective recruiting document for 'The Lesbian Nation' (Johnston, 1974)! Moreover, Wilton's final flourishing gesture her elaborately worked allegory of sexual desire through the metaphor of food only serves to increase such a potential. Thus, if lesbian experience be the 'the most wonderful gourmet feast' (p. 96) then why not eat, drink and be merry?

\section{references}

Kay Inckle

Johnston, J. (1974) Lesbian Nation: The Feminist Solution, London: Simon \& Schuster Books.

Wilton, T. (1996) Finger Licking Good: The Ins \& Outs of Lesbian Sex, London: Cassell.

Wilton, T. (2002) Unexpected Pleasures: Leaving Heterosexuality for a Lesbian Life, London: Diva Books.

doi:10.1057/palgrave.fr. 9400343 